\title{
APOIO PEDAGógICO E ASSISTÊNCIA ESTUDANTIL: UM ESTADO DA ARTE
}

\author{
PEDAGOGICAL SUPPORT AND STUDENT ASSISTANCE: A STATE OF THE \\ $A R T$
}

\author{
(9) Carlos Eduardo Sampaio Burgos Dias \\ Doutorando pelo Programa de Pós-Graduação em Educação da Unicamp. Pedagogo da \\ Universidade Federal de São Paulo (UNIFESP) na Escola Paulista de Política, Economia e Negócios \\ (EPPEN) no Núcleo de Apoio ao Estudante (NAE) \\ Osasco, SP - Brasil. \\ carlos.dias@unifesp.br
}

\begin{abstract}
Resumo: Este trabalho é uma revisão bibliográfica sobre apoio pedagógico e assistência estudantil. Com a expansão do ensino superior no Brasil nas últimas duas décadas e a diversificação do seu público, políticas públicas como o PNAES ganharam grande importância para a permanência dos estudantes no ensino superior, no entanto, o auxílio material parece não ser suficiente para garantir essa permanência, e outras ações como o apoio pedagógico aparecem como possibilidade de políticas institucionais. Nesse sentido, entre os dias 19 e 22 de junho de 2019 foi feito um levantamento em duas bases de dados de publicações que relacionassem pesquisas sobre apoio pedagógico, assistência estudantil e ensino superior. Ao final selecionamos 27 trabalhos para uma análise mais detalhada. De maneira geral, a revisão bibliográfica apontou para uma lacuna, pois nenhum dos trabalhos abordou diretamente a ideia de Apoio Pedagógico.
\end{abstract}

Palavras-chave: Ensino superior. Assistência estudantil. Apoio pedagógico. Permanência estudantil. Política pública.

\begin{abstract}
This work is a literature review on pedagogical support and student assistance. With the expansion of higher education in Brazil in the last two decades and the diversification of its public, public policies such as the PNAES have gained great importance for the permanence of students in higher education, however, the material aid does not seem to be sufficient to guarantee this permanence, and other actions such as pedagogical support appear as a possibility for institutional policies. In this sense, between June 19 and 22, 2019, a survey was carried out in two databases of publications that related research on pedagogical support, student assistance and higher education. At the end we selected 27 papers for a more detailed analysis. In general, the literature review pointed to a gap, as none of the works directly addressed the idea of Pedagogical Support.
\end{abstract}

Keywords: Higher education. Student assistance. Pedagogical support. Student permanence. Public policy.

Resumen: Este trabajo es una revisión bibliográfica sobre apoyo pedagógico y asistencia al estudiante. Con la expansión de la educación superior en Brasil en las últimas dos décadas y la diversificación de su público, políticas públicas como el PNAES han ganado gran importancia para la permanencia de los estudiantes en la educación superior, sin embargo, la ayuda material no parece ser suficiente para garantizar esta permanencia, y otras acciones como el apoyo pedagógico aparecen como una posibilidad para las políticas institucionales. En este sentido, entre el 19 y 22 de junio de 2019, se realizó una búsqueda en dos bases de datos de publicaciones que relacionaban investigaciones sobre apoyo pedagógico, asistencia al estudiante y educación superior. Al final, seleccionamos 27 artículos para un análisis más detallado. En general, la revisión de la literatura señaló una brecha, ya que ninguno de los trabajos abordó directamente la idea de Apoyo Pedagógico.

Palabras-clave: Educación superior. Asistencia estudiantil. Apoyo pedagógico. Residencia de estudiantes. Política pública.

\section{Para citar - ABNT NBR 6023:2018}

DIAS, Carlos Eduardo Sampaio Burgos. Apoio pedagógico e assistência estudantil: um estado da arte. Cadernos de Pós-graduação, São Paulo, v. 19, n. 2, p. 126-145, jul./dez. 2020. Disponível em: https://doi.org/10.5585/cpg.v19n2.18136. 


\section{Introdução}

Este trabalho busca demonstrar o estado da arte sobre o Apoio Pedagógico no Ensino Superior, em especial vinculado às ideias de assistência e permanência estudantil. Para Ferreira (2002) essas pesquisas são de caráter bibliográfico,

[...] elas parecem trazer em comum o desafio de mapear e de discutir uma certa produção acadêmica em diferentes campos do conhecimento, tentando responder que aspectos e dimensões vêm sendo destacados e privilegiados em diferentes épocas e lugares, de que formas e em que condições têm sido produzidas certas dissertações de mestrado, teses de doutorado, publicações em periódicos e comunicações em anais de congressos e de seminários (FERREIRA, 2002, p.258).

Ainda segundo a autora, essas pesquisas também:

[...] são reconhecidas por realizarem uma metodologia de caráter inventariante e descritivo da produção acadêmica e científica sobre o tema que busca investigar, à luz de categorias e facetas que se caracterizam enquanto tais em cada trabalho e no conjunto deles, sob os quais o fenômeno passa a ser analisado (FERREIRA, 2002, p.258).

Assim, este trabalho é uma pesquisa de revisão bibliográfica realizada entre os dias 19 e 22 de junho de 2019 na Biblioteca Digital de Teses e Dissertações (BDTD) do Instituto Brasileiro de Informação em Ciência e Tecnologia (IBICT), ligado ao Ministério da Ciência, Tecnologia, Inovações e Comunicações, e na base de dados da Scielo Brasil.

O trabalho faz parte de uma pesquisa de doutorado que busca identificar as ações/políticas institucionais de apoio pedagógico no âmbito dos serviços de assistência estudantil em universidades federais brasileiras. Esse estudo está inserido no campo de pesquisas sobre ensino superior, naquilo que Neves et al (2018) classificam como um dos dois grandes quadros interpretativos: "os que procuram enfatizar o potencial de contribuição das instituições de ensino superior para a democratização das sociedades contemporâneas, para a inovação cultural e para a formação de indivíduos intelectualmente autônomos" (NEVES et al., 2018, p.25).

Segundo as autoras, ainda que, mesmo de forma lenta, os temas pesquisados tenham tido uma constante diversificação, "a produção acadêmica no Brasil sobre o ensino superior parece sugerir que ainda estamos sob o impacto de buscar compreender os efeitos da expansão recente do sistema nacional" (NEVES et al., 2018, p.32).

É dentro deste campo que a pesquisa de doutorado busca compreender como tem sido o atendimento das demandas por apoio pedagógico no contexto da expansão do ensino superior brasileiro nas últimas décadas, em seu processo de massificação (TROW, 2005) que incluiu novos públicos (DIAS, 2014 e 2015, RISTOFF, 2014, HERINGER, 2011 e 2014 e SAMPAIO, 2014). A inclusão dessa diversidade de públicos (SAMPAIO, 2014), geralmente de primeira geração e sem 
background cultural do ensino superior (DIAS, 2014 e 2015a) tem exigido das instituições novas políticas e ações para o atendimento desse público, incluindo, ações de apoio pedagógico. Muitas dessas ações têm se dado nos serviços de apoio aos estudantes vinculados aos assuntos estudantis, denominação internacional (UNESCO, 2009) ou ligados à assistência estudantil, no caso brasileiro. Nesse sentido, conhecer como têm se constituído as ações de apoio pedagógico contribui para os objetivos de democratizar o ensino superior (COULON, 2017) para além do acesso (RISTOFF, 2014; HERINGER, 2014; DIAS, 2014).

Andrade e Teixeira (2017) apontam que "apesar da importância que representa para a grande maioria da clientela estudantil das escolas públicas de ensino superior no Brasil, o tema da assistência estudantil ainda é pouco pesquisado". Eles apontam que o "entendimento de assistência estudantil era atrelado à ideia de apoio à moradia e à alimentação, destacando a pertinência do auxílio financeiro a fatores de ordem econômica" (ANDRADE \& TEIXEIRA, 2017, p.516). Outros trabalhos, como o de Heringer (2014), apontam a escassez de estudos na temática da assistência estudantil que, quando existentes, buscam avaliar a implementação de mecanismos pecuniários como bolsas e auxílios de ordem material (moradia, alimentação e transportes). Assim, formas de apoio imateriais, como saúde, esportes, cultura e apoio pedagógico, pouco, ou quase nada aparecem na literatura acadêmica brasileira.

\section{As publicações sobre Apoio Pedagógico nas bases de dados}

A busca de publicações sobre Apoio Pedagógico foi realizada entre os dias 19 e 22 de junho de 2019 em duas bases de dados, uma voltada a teses e dissertações e outra de artigos.

$\mathrm{Na}$ Biblioteca Digital de Teses e Dissertações (BDTD) do Instituto Brasileiro de Informação em Ciência e Tecnologia (IBICT) ligado ao Ministério da Ciência, Tecnologia, Inovações e Comunicações, que disponibiliza um total de 406.143 dissertações e 147.364 teses referentes a colaboração de 114 instituições entre universidades federais, estaduais, particulares e confessionais foram localizados 257 trabalhos a partir da expressão "assistência estudantil". Quando utilizada a expressão "permanência estudantil” foram localizados 205 trabalhos. Na busca avançada combinando as expressões "assistência estudantil” e "apoio pedagógico" foram localizados apenas oito trabalhos. Já quando combinadas as expressões "assistência estudantil" e "serviços de apoio" foram localizados 30 trabalhos. E, combinando "assistência estudantil" e "PNAES" foram localizados 70 trabalhos. Quando a expressão combinada foi "permanência estudantil" com "apoio pedagógico" foram localizados 11 trabalhos, já quando combinada a expressão "serviços de apoio" foram localizados 26 trabalhos e quando combinada com a expressão "PNAES" foram localizados 61 trabalhos. 
A escolha dessas expressões está ligada ao objetivo da pesquisa de doutorado, que é conhecer as políticas e ações de apoio pedagógico das universidades federais brasileiras vinculadas aos serviços de apoio ao estudante, que geralmente têm como recorte de público os estudantes atendidos por alguma política de assistência estudantil, podendo inclusive, a partir do PNAES, o próprio "apoio pedagógico" ser considerado uma ação ou política institucional inserida em suas políticas de assuntos estudantis.

Nesse sentido, do total de trabalhos, foram pré-selecionados aqueles que combinaram as expressões "assistência estudantil, permanência estudantil, apoio pedagógico e serviços de apoio". Assim, foram localizados inicialmente, nessa base de dados, 75 trabalhos. Numa primeira análise após eliminar os trabalhos que apareceram em mais de uma busca e naqueles que não abordavam o ensino superior, foram selecionados 34 trabalhos publicados entre 2008 e 2019. Um dado interessante é que do total de 34 autores, apenas sete não eram ligados a instituições de ensino superior. Do total de 27 autores ligados ao ensino superior quatro são docentes e os demais são técnicos administrativos, principalmente de instituições federais, com maior destaque para os assistentes sociais, profissão de 16 desses autores. A maioria (22) desses 34 trabalhos foi defendido em programas de pós-graduação ligados a universidades federais, seguido das universidades estaduais (6), confessionais (4), particulares (1) e internacional (1). A maior parte dos trabalhos são estudos de caso que buscam avaliar as políticas de assistência estudantil das instituições pesquisadas que, em boa parte das vezes, são as instituições às quais os autores são vinculados profissionalmente, ou seja, de certa maneira é quase que uma avaliação do próprio trabalho.

Num primeiro momento, os trabalhos que analisaram Institutos Federais e CEFETs foram mantidos para a análise dos seus conteúdos, mas que ao longo desta pesquisa não serão utilizados para efeitos de ilustração ou comparação, dado que nestas instituições também se atendem estudantes de ensino médio ligados aos cursos técnicos e, como estes seguem outras legislações e regulamentações, não serão objeto desta pesquisa.

Do total de 257 trabalhos encontrados com a expressão "assistência estudantil", a maioria (236) são dissertações. Institucionalmente, as universidades que aparecem com mais trabalhos defendidos com 18 cada são a UFC, UFJF e UNB, seguidas com 16 trabalhos defendidos a UFBA e UFPE. Os Programas de Pós-Graduação com mais defesas são educação e serviço social com 18 trabalhos cada, seguidos do mestrado em gestão e avaliação de políticas públicas, com 09 trabalhos defendidos.

Em processo semelhante de pesquisa, porém utilizando a base de dados da Scielo Brasil, a busca alcançou menos trabalhos. Quando pesquisado apenas a partir da expressão "ensino superior" foram localizadas 567 publicações, porém quando combinada com a expressão "estudante" 
o número foi reduzido a apenas 29 publicações. Quando utilizadas apenas as expressões "permanência estudantil" ou "serviço de apoio ao estudante" não foram localizadas publicações, e quando utilizada a expressão "assistência estudantil” foram localizadas quatro publicações e quando utilizada a expressão "PNAES" foram localizadas apenas duas publicações. Inicialmente a pesquisa com a expressão “apoio pedagógico” remeteu a uma publicação, que, após rápida análise, verificouse ser referente à educação básica. Assim, optou-se por uma análise inicial das 29 publicações localizadas a partir das expressões "ensino superior" e "estudante" ficando ao final 13 publicações.

\section{Um breve balanço sobre o Apoio Pedagógico}

O estudo mais recente encontrado na plataforma do IBICT foi o de Mauricio (2019), tratase de um estudo de caso avaliando o PNAES na Universidade Federal do Tocantins e, em uma de suas conclusões, aponta que "em algumas áreas a UFT ainda não conseguiu desenvolver ações, isso porque a instituição prioriza as áreas de assistência básicas, devido à limitação dos recursos para atender o elevado número de estudantes vulneráveis" (MAURICIO, 2019, p.58).

Em outro estudo de caso, também da UFT, Fernandes (2018), buscou identificar se a política de assistência estudantil contribui com a melhoria da qualidade de vida e do desempenho acadêmico dos estudantes assistidos pelo PNAES na UFT. Segundo a autora os resultados apontam que a assistência estudantil se constitui num apoio fundamental para a permanência dos estudantes com vulnerabilidade socioeconômica, porém nem sempre sendo suficientes para garantir o êxito com o desempenho acadêmico destes estudantes beneficiários.

Araújo (2017) buscou analisar as condições de permanência ofertadas pela política de assistência estudantil do Instituto Federal do Ceara campus Iguatu voltadas aos estudantes de ensino superior entre os anos de 2011 e 2015. Segundo a autora:

Observou-se que a taxa de permanência dos beneficiários do Programa de Auxílios Pecuniários de todos os cursos analisados, Serviço Social (79,5\%), Química (68,7\%) e Irrigação e Drenagem $(60,2 \%)$ foi superior a taxa de permanência dos não beneficiários, $35,4 \%, 25,4 \%$ e $14,2 \%$ para os mesmos cursos (ARAUJO, 2017, p.9).

Vargas, MW (2017), buscou em seu estudo avaliar a política de assistência estudantil na UNIPAMPA a partir do PNAES comparando-a a das demais instituições federais de ensino superior da "metade sul do estado do Rio Grande do Sul". A autora analisou documentos institucionais e entrevistou gestores e profissionais da assistência estudantil das IFES dessa região geográfica e concluiu que a "Unipampa atende a todos os eixos do PNAES mediante as ações executadas". Ela também verificou que há certa convergência de ações entre as IFES comparadas havendo disparidades em termos de percentuais investidos em cada ação institucional e verificou 
diferenças nas ações de apoio pedagógico e atendimento em saúde. Ela também apontou a necessidade em se melhorar os canais de divulgação "de relatórios de dados de planejamento e de execução das ações da política, e a inexistência de um sistema formalmente estruturado de avaliação destas ações" (VARGAS, MW, 2017, p. IX).

Abreu (2017) buscou identificar os motivos da evasão dos estudantes de cursos de graduação presencial atendidos pelos programas de assistência estudantil do Instituto Federal do Paraná (IFPR) campus Londrina. A autora analisou os documentos institucionais e entrevistou estudantes beneficiados por programas de apoio estudantil e evadidos da instituição. Segundo a autora, os resultados indicaram que a evasão entre estes estudantes foi um fenômeno multifatorial e que a política de assistência estudantil demonstrou ser um elemento fundamental para a permanência dos estudantes. Porém, ainda segundo Abreu (2017), "esta política, de forma isolada, não garante a permanência. É necessário que esteja sintonizada com a proposta pedagógica institucional, sob pena de se tornar fragmentada e parcializada no atendimento às demandas dos estudantes" (ABREU, 2017, p.9).

Farias (2018), também buscou avaliar a Política de Assistência Estudantil, sendo mais um estudo de caso, desta vez sobre o Instituto Federal de Educação, Ciência e Tecnologia da Paraíba - Campus João Pessoa e a partir da percepção dos estudantes. É mais um estudo de caso, do curso de Design de Interiores e beneficiários das políticas locais. Segundo o autor, os resultados apontaram para:

um processo de desconhecimento por parte dos discentes dos objetivos da Política de Assistência Estudantil, reduzindo-a ao apoio financeiro de programas de alimentação, transporte e moradia, desconhecendo serviços institucionais que venham a viabilizar de maneira efetiva a sua permanência. (FARIAS, 2018, p.13).

Para Farias (2018), a Política de Assistência Estudantil do IFPB é "limitada ao repasse financeiro aos estudantes" o que reforçaria "a lógica de repasse de recursos via transferência de renda", presente, segundo ele, na maioria das Políticas Sociais Brasileiras, o que "contribui para a falta de clareza e distinção das peculiaridades existentes entre a Assistência Estudantil e a Política Pública de Assistência Social". O autor também destaca em seu estudo a "inexistência de ações que visem ao acompanhamento pedagógico destes estudantes e a falta de compreensão do papel da Assistência Estudantil em sua trajetória acadêmica" (FARIAS, 2018, p.13). Para ele, ficou evidente uma maior preocupação do IFPB em priorizar demandas materiais em detrimento de demandas simbólicas dos estudantes.

Magalhães (2019) buscou em seu estudo desenvolver um modelo de avaliação e gestão da política de cotas em Instituições federais de Ensino Superior (IFES); para isso, fez um estudo de 
caso com a Universidade Federal de Goiás (UFG). Ele definiu cinco eixos para essa avaliação: 1Recepção e Acolhimento; 2- Apoio Pedagógico; 3-Assistência Estudantil; 4-Acompanhamento do desempenho e evasão e 5-Avaliação da política de cotas. De acordo com o autor, os resultados indicaram que o apoio pedagógico foi o eixo no qual foram realizadas mais ações na gestão da política de cotas da UFG. Ele concluiu que muitas IFES possuem dificuldades em avaliar a gestão das suas políticas de cotas e aponta que o modelo desenvolvido em sua pesquisa pode contribuir com outras IFES permitindo que elas avaliem suas políticas, podendo melhorá-las.

Botelho (2016) analisou a relação entre o movimento estudantil da Universidade Federal de Viçosa (UFV) e as políticas de assistência ao estudante praticadas por esta universidade. Segundo ela, nas entidades estudantis também se pratica algum tipo de suporte aos estudantes, que algumas vezes dialoga com as políticas institucionais e outras vezes não. Assim, a pesquisa buscou avaliar as discussões de temas como corpo, violência, aborto, racismo, segurança, dentre outros, que se deram nas relações entre o movimento estudantil e os órgãos da assistência estudantil da UFV.

Senger (2018) buscou avaliar o Programa Auxílio Estudantil (PAE), da Universidade Tecnológica Federal do Paraná (UTFPR), mais especificamente do campus Toledo. A autora buscou saber em que medida este Programa atingiu a sua finalidade, de apoiar a permanência dos estudantes com dificuldades socioeconômicas. A autora analisou os editais de seleção desses estudantes beneficiários, os dados acadêmicos dos estudantes beneficiados, analisando as entrevistas realizadas pelo Núcleo de Acompanhamento Psicopedagógico e Assistência Estudantil com os estudantes que desistem/trancam seus cursos, além de pesquisa de campo. A autora concluiu que o PAE é relevante para a permanência dos estudantes atendidos, contribuindo tanto na parte financeira como psicológica, mesmo reconhecendo que o valor dos auxílios é insuficiente para que os estudantes se mantenham apenas com ele e destacou as dificuldades em atender a todos os que necessitam da assistência estudantil, dado a expressiva demanda que gera lista de espera.

Creste (2013), buscou analisar a importância dos Serviços de Apoio Psicopedagógico ao estudante de Medicina, uma vez que, segundo ela, as pesquisas sobre esses tipos de serviços voltados a estudantes de Medicinas se fazem cada vez mais necessários "devido ao fato de sua relação direta com o desempenho acadêmico e à boa formação do egresso” (CRESTE, 2013, p.8).. Ainda segundo a autora, sejam esses serviços de "caráter curativo ou preventivo, podem, num ambiente humanizador, compreender, conhecer e acompanhar a vida do acadêmico, proporcionando-lhe momentos de reflexão, tomada de consciência e possíveis soluções" (CRESTE, 2013, p.8). Para isso, ela buscou identificar serviços de referência no Brasil que pudessem subsidiar a implementação de um serviço congênere em uma Instituição de Ensino Superior Particular. Segundo a autora, os resultados apontaram uma dificuldade de contatar os 
Serviços de Apoio Psicopedagógico das IES que, em alguns casos ainda disponibilizam informações, mas não possuem mais os serviços. Porém, aqueles que disponibilizam este tipo de serviço o valorizam apesar da falta de condições adequadas para o seu funcionamento. Ainda segundo a autora, muitas instituições não valorizam esse tipo de serviço não o considerando prioritário, o que leva a uma estrutura insuficiente e falta de equipe técnica. No entanto, para ela, ao tomar como exemplo o Serviço de Apoio Psicopedagógico de uma instituição pública do interior de São Paulo, verificou que este proporciona aos seus estudantes um "apoio emocional frente às dificuldades acadêmicas e pessoais encontradas no percurso estudantil”' (CRESTE, 2013, p.87).

Marques (2014) buscou avaliar a assistência estudantil a partir da efetividade do Programa Nacional de Assistência Estudantil (PNAES) na Universidade Federal de Campina Grande (UFCG) e na Universidade Federal da Paraíba (UFPB) a partir da perspectiva dos assistentes sociais. Segundo ele, os resultados apontaram para a não execução das 10 áreas temáticas do PNAES na UFCG e UFPB. Para ele, destacaram-se apenas as ações voltadas para Moradia e Alimentação, e algumas de esportes e de saúde. Dessa forma, ele concluiu que a "Assistência Estudantil não é universalizada, mas, limitada a ações focalistas, residuais e excludentes, o que rebate na prática profissional do/a assistente social, marcada pela seletividade sob o signo clientelista e conservador" (MARQUES, 2014, p.9).

Borsato (2015), também buscou analisar a implementação de políticas de assistência estudantil na visão das assistentes sociais. Ela fez um estudo de caso da Universidade Federal de Mato Grosso do SUL (UFMS) em que fez uma análise documental dos atos normativos e administrativos da UFMS, além de entrevistas com as assistentes sociais responsáveis pela assistência estudantil na UFMS. A partir desses dados a autora identificou que a criação do PNAES "promoveu um novo status à Assistência Estudantil da UFMS". Entretanto ela destaca que mesmo com esse ganho de visibilidade institucional, suas ações foram desenvolvidas de forma a priorizar as bolsas e auxílios financeiros com exigência de contrapartidas e de forma focalizada, o que, segundo ela, tem penalizado e diferenciado os acadêmicos pobres, que "são triplamente penalizados e responsabilizados exclusivamente pelo rendimento acadêmico" (BORSATO, 2015, p.182), contribuindo assim para a construção de uma "universidade dualizada".

Osse (2008) buscou mapear em seu estudo as condições psicológicas, sociais e de qualidade de vida dos estudantes residentes na moradia estudantil da UnB. Seu intuito foi poder, ao final da pesquisa, subsidiar programas de proteção, prevenção e assistência estudantil. Segundo a autora, a procura por assistência psicológica em programas da UnB era "composta em sua maioria por jovens universitários entre 17 e 25 anos, em fase crítica de desenvolvimento psicossocial, experimentando muitas mudanças (...)" (OSSE, 2008, p.9) inclusive, sair da casa dos pais. A partir 
de questionários que buscaram conhecer os hábitos desses estudantes, ela destacou que os resultados apontaram para uma realidade preocupante: “jovens na maioria com até 25 anos de idade, com dificuldades para a sua manutenção material na universidade" (OSSE, 2008, p.9). Ainda segundo ela, foram "identificados, em sua maioria, pródromos que indicaram ansiedade, depressão e dificuldades em aceitar/procurar ajuda" (OSSE, 2008, p.9). Seguindo nessa linha de interpretação dos resultados, ela verificou que questões financeiras combinadas a um ambiente social de complexidade com um "[...] emaranhado de relações e a carência de orientação e apoio identificados, favorecerem o aparecimento de comportamentos de risco como tentativa de solução de problemas relacionados ao sofrimento psíquico" (OSSE, 2008, p.9). Neste sentido, ela apontou que apesar de, à época, existirem programas estudantis na UNB, estes não conseguiam cobrir toda a demanda, ficando evidente, a "necessidade de implementação de investimentos que privilegiem a saúde física e mental e que possibilitem não só a permanência na universidade, mas uma permanência com qualidade" (OSSE, 2008, p.9). Assim, ela sugeriu programas mais abrangentes que tivessem como objetivo a melhora do rendimento acadêmico e da qualidade de vida.

O estudo mais recente localizado na Scielo é o que apresenta mais características em comum com os objetivos da pesquisa de doutorado. Nele, Donida e Santana (2019) analisaram as ações de apoio pedagógico de uma universidade federal no sul do país. Eles inserem seu estudo no campo do ensino superior e das recentes políticas de expansão do mesmo e destacam as mudanças no perfil dos estudantes na última década a partir da implementação de algumas políticas públicas, sobretudo as de ação afirmativa. A pesquisa utilizou dados quantitativos e qualitativos com entrevistas semiestruturadas aplicadas presencialmente com os integrantes da equipe do Apoio Pedagógico: a tutora, o profissional da CAE e três estudantes com dificuldades de leitura e/ou escrita e um com Transtorno Funcional, e uma análise documental das políticas públicas e ações institucionais de apoio pedagógico. Segundo as autoras, os resultados apontam para uma limitação do programa de apoio pedagógico, visto que não "atingem todos os estudantes, a adesão dos cursos aos programas ofertados pelo Apoio Pedagógico é baixa e a divulgação ainda é insuficiente" (DONIDA e SANTANA, 2019, p.15). Além disso, elas apontam que os estudantes com dificuldades acadêmicas se sentem excluídos pelos docentes e demais colegas, e que essas dificuldades atrapalham suas trajetórias e permanência na instituição. Para elas, essas "dificuldades de caráter mais específico citadas pelos universitários, as quais se somam a um histórico de fracasso escolar, que tende a agravar a situação do estudante” (DONIDA e SANTANA, 2019, p.15). Assim, elas defendem a necessidade de outras medidas que possam promover a inclusão dos estudantes com dificuldades de leitura e escrita, de forma a garantir a permanência destes e consequentemente reduzir as taxas de evasão. Elas citam como medidas: "curso de formação docente, programa de 
apoio ao estudante mais direcionado para cada necessidade, oficinas de letramento, palestras para a comunidade acadêmica e divulgação do trabalho de Apoio Pedagógico de forma mais efetiva" (DONIDA e SANTANA, 2019, p.15). Por fim, elas destacam que as "ações propostas devem ainda envolver uma equipe de profissionais que tenha formação para orientar/acolher esses estudantes" (DONIDA e SANTANA, 2019, p.15).

Em seu trabalho, Coulon (2017), busca demonstrar, a partir do conceito de afiliação, as diferenças entre a democratização do acesso e do acesso ao saber. Para o autor "a passagem do ensino médio ao superior é acompanhada por mudanças importantes em sua relação com o saber: as regras não são as mesmas, elas são mais sofisticadas, complexas, simbólicas e devem ser rapidamente assimiladas pelos novos estudantes" (COULON, 2017, p.1239). Ele argumenta que tanto Brasil como a França passaram por um processo de massificação do ensino superior nos últimos anos e que alguns autores defendem esse processo como democratização. Para ele, os estudantes de primeiro ano ao ingressarem na universidade possuem níveis muito heterógenos, enfrentando muitas dificuldades de adaptação. Assim, ele demonstra a partir de outras pesquisas que os estudantes que não conseguem se afiliar ao universo acadêmico fracassam, pois, segundo Coulon, "o sucesso universitário passa pela aprendizagem de um verdadeiro ofício de estudante" (COULON, 2017, p.1242). Assim, neste trabalho o autor discute duas experiências "a escrita cotidiana" e a "aprendizagem da metodologia documental" a possibilidade de uma pedagogia da afiliação. Ele argumenta que ambas são atividades simples de serem realizadas e eficazes para que os estudantes se insiram no seu novo mundo, o mundo das ideias (COULON, 2017, p. 1242).

Já no estudo de Matta, Lebrão e Heleno (2017), os autores fazem uma revisão de artigos publicados entre 2005 e 2015 nas bases eletrônicas da Biblioteca Virtual de Saúde (BVS), Scielo Brasil e Portal de Periódicos Eletrônicos de Psicologia (PePSIC). Eles buscaram artigos referentes à adaptação universitária relacionada às vivências acadêmicas, rendimento e evasão em cursos de Engenharia. Todos os artigos selecionados (16) utilizaram algum questionário como instrumento de coleta de dados. Os autores constataram a escassez do tema da adaptação universitária nos cursos de engenharia e concluíram, a partir desta revisão, que os relacionamentos interpessoais podem favorecer o rendimento acadêmico e adiar a evasão, assim como os serviços de apoio aos estudantes. Os autores destacam a importância das instituições se planejarem para o processo de adaptação do estudante à vida acadêmica no ensino superior, e apontam que "atividades de integração e serviços de apoio aos estudantes, seja psicológico, seja psicossocial, poderiam facilitar a integração à vida acadêmica e contribuir para a permanência dos estudantes na instituição" (MATTA, LEBRÃO e HELENO, 2017, p.589). 
Em seu trabalho, Vargas, MLF (2011) analisou uma amostra de egressos da UFMG buscando examinar as conexões entre as desigualdades de acesso e permanência no ensino superior, a assistência estudantil e a inserção profissional. Ela buscou comparar a inserção profissional de antigos bolsistas de assistência estudantil com não bolsistas e concluiu que do ponto de vista dos níveis de remuneração após a posse do diploma não havia desigualdade de condições no mercado de trabalho. Entretanto, ela verificou a partir da amostra de egressos analisadas que a remuneração dos ex-bolsistas foi afetada pelos mesmos fatores de não bolsistas, como carreira, titulação e setor de atuação, apontando que a renda tem forte relação com a carreira, como apontam outros estudos, segundo a autora. Ela concluiu que a assistência estudantil colabora para que estudantes pobres obtenham sua diplomação e tornem-se profissionais qualificados no mercado de trabalho ampliando suas possibilidades de ascender socialmente.

Na pesquisa de Andriola e Suliano (2015), os autores analisam os impactos da presença da Universidade Federal do Ceará (UFC) nos municípios do interior do estado do Ceará que receberam campus da UFC após a adesão desta ao Programa de Apoio a Planos de Reestruturação e Expansão das Universidades Federais (Reuni). O estudo coletou dados junto a 129 docentes, 503 discentes dos três campi avançados da UFC, nos municípios de Sobral, de Quixadá e da Região do Cariri (Juazeiro do Norte, Crato e Barbalha), e com 191 moradores locais. Segundo os autores, os resultados apontaram que todos os grupos pesquisados nos três campi estudados "convergiram para a aceitação de que a UFC causou impactos sociais positivos nos municípios cearenses do interior" (p.282). Segundo os autores, os principais impactos foram:

a) Incremento das oportunidades de a população local ter acesso aos novos cursos de graduação da UFC, bem como às atividades e/ou ações de qualificação profissional. b) Dinamização econômica local, implicando crescimento municipal e incremento das oportunidades de inserção laboral para os moradores da região. c) Geração de maior quantidade e diversidade, além de melhores postos de trabalho para os moradores locais (ANDRIOLA \& SULIANO, 2015, p.294).

Mesmo este estudo fugindo ao nosso objeto de estudo principal, ele se insere no contexto das discussões sobre a expansão do Ensino Superior brasileiro, sobretudo das universidades federais e aponta para outros benefícios dessa expansão de forma indireta, o que nos ajuda a compreender as justificativas nacionais para a expansão do ensino superior federal brasileiro.

Silva (2017) buscou conhecer e refletir sobre as concepções de docentes de cursos da área de exatas em relação às ações afirmativas na universidade. $\mathrm{O}$ autor organizou seus resultados em quatro temas: 
“[...] além de um assistencialismo; singularidades, particularidades e desempenho de estudantes beneficiados por ações afirmativas; a questão da permanência; e valorização dos docentes envolvidos em práticas voltadas para a permanência do estudante beneficiado por ações afirmativas" (SILVA, 2017, p.820).

Ao longo do trabalho o autor dialoga com seus entrevistados, docentes de exatas, trazendo à tona as diferentes reflexões desses docentes a respeito dessa temática. Um dos principais debates é na tensão do desenvolvimento de ações pedagógicas voltadas para a permanência dos estudantes. Segundo o autor, uma das estratégias de permanência mais utilizadas visando diminuir as dificuldades do cotidiano referentes às disciplinas de matemática foi a criação de "ações remediais", como os "cursos de nivelamento", que, segundo ele, muitas vezes são embutidos na grade curricular dos cursos. Segundo Silva (2017), esse tipo de ação tem gerado uma tensão entre os docentes nos departamentos de matemática, uns por não acreditarem que uma simples disciplina promova mudanças e outros considerando não ser possível modificar hábitos de estudos utilizando simplesmente uma disciplina. Complementam o desconforto dos docentes segundo Silva (2017, p.843), o fato da não valorização do envolvimento desses docentes em "ações pedagógicas direcionadas à permanência de estudantes pertencentes a grupos sub-representados". Ele argumenta com a fala de uma docente que diz que esse envolvimento exige engajamento dos docentes, muitas vezes se tornando "um quarto elemento da atribuição docente" (SILVA, 2017, p.843). O autor não a explicita em suas reflexões, mas fica subentendido que os três elementos seriam a pesquisa, o ensino e a extensão, pois segundo os seus entrevistados, a pesquisa é a atividade mais valorizada na universidade e que essas ações pedagógicas direcionadas a permanência não seriam valorizadas, pois por ser uma atividade para além do ensino seriam talvez definidas como de assistência ("quarto elemento"), não consideradas do ponto de vista da progressão na carreira.

Garrido e Mercuri (2013) analisaram a produção científica nacional sobre moradias estudantis universitárias. As autoras localizaram 23 trabalhos publicados entre o ano 2000 e 2009. Elas organizaram os resultados em três categorias: o estudante morador, a moradia estudantil e as ações da assistência estudantil. Elas verificaram que embora o tema das moradias universitárias seja amplo na produção científica internacional, no Brasil o tema ainda é escasso e, segundo elas, a visão da moradia como espaço de formação está pouco presente. Assim, elas sugerem novas investigações que "busquem conhecer a realidade desses ambientes e os impactos produzidos sobre os estudantes" (GARRIDO e MERCURI, 2013, p.87). Elas argumentam que uma vez essas moradias sendo responsabilidade das instituições de ensino superior, tais estudos poderiam subsidiar medidas voltadas à formação dos estudantes.

Num estudo mais recente sobre as moradias estudantis, Lacerda e Valentini (2018), avaliaram o impacto da moradia estudantil sobre a vida acadêmica dos estudantes, analisando a 
permanência destes na universidade. O estudo comparou dados de residentes e não residentes e os dados indicaram uma melhora do rendimento acadêmico dos residentes e que, após o ingresso nas moradias, os residentes trancaram menos disciplinas que os não residentes. Assim, os autores concluem que as moradias trazem impactos positivos para a vida acadêmica dos estudantes, contribuindo com seu desempenho acadêmico e consequentemente para a sua permanência na universidade.

Ristoff (2014) discute em seu trabalho o perfil dos estudantes de ensino superior no Brasil e analisa até que ponto as políticas recentes de expansão do ensino superior brasileiro ${ }^{1}$ alteraram, ou não, o perfil socioeconômico dos estudantes de ensino superior no Brasil. Ele utilizou como principal fonte de informações o questionário socioeconômico do Exame Nacional de Desempenho do Estudante (ENADE) e concluiu que, se por um lado houve um avanço em termos de diversificação do perfil dos estudantes, no período compreendido nesta pesquisa 2004 a 2012, "em média o campus brasileiro continua significativamente mais branco que a sociedade brasileira" (RISTOFF, 2014, p.742). Ele complementa afirmando que o "campus brasileiro como um todo ainda está longe de refletir a nova realidade populacional revelada pelo último Censo do IBGE, na qual, pela primeira vez, pretos e pardos formam o grupo majoritário da população brasileira, com 51\%, contra 48\% de brancos" (RISTOFF, 2014, p.742). Assim, o autor destaca que embora as políticas possam ser consideradas um avanço e que os resultados da promulgação da Lei de Cotas ainda estariam por alterar esse perfil, na média, o perfil dos estudantes de graduação ainda estava distante do perfil da população brasileira e que a principal correção a ser feita estava para os cursos de alta demanda.

O trabalho de Andrade e Teixeira (2017) buscou relacionar a intenção de permanência, o desempenho acadêmico e a percepção de desenvolvimento psicossocial com as dez áreas do PNAES, incluindo o apoio pedagógico. Os autores argumentam que o objetivo do PNAES, enquanto política pública é reduzir a evasão e melhorar o desempenho acadêmico dos estudantes, entretanto, segundo eles, estudos têm apontado que a decisão de permanecer num curso e na instituição, assim como o seu desempenho acadêmico e o seu desenvolvimento psicossocial, é afetada por fatores pessoais, relacionais e acadêmicos. Segundo eles, os dados deste estudo foram coletados numa "nova universidade multicampi" e os resultados indicaram "correlações baixas ou inexistentes das variáveis-alvo com as áreas do PNAES" (ANDRADE e TEIXEIRA, 2017, p.512).

Recktenvald et al (2018) fazem uma análise compreensiva do PNAES a partir de diferentes olhares epistemológicos. Eles caracterizam o PNAES como um programa de modelo social desenvolvimentista, vigente, segundo eles, no período entre 2203 e 2016. Para eles, o artigo também reflete a experiência dos autores enquanto gestores do campo da assistência estudantil e 
pesquisadores em três universidades federais brasileiras. Eles tomam como abordagem metodológica a teoria interpretativista, e apontam algumas distintas epistemologias para análise do PNAES: o positivismo, o utilitarismo que dele emerge, o funcionalismo, o sistemismo, a dialética e a complexidade. Ao longo do trabalho eles descrevem essas epistemologias relacionando-as com o PNAES e apontam para a necessidade de o programa ser analisado sob várias dessas epistemologias.

Na linha da avaliação do PNAES como uma política pública, Dutra e Santos (2017), buscam discutir as diferentes concepções sobre o Programa a partir da regulamentação do mesmo em âmbito governamental, que é fato recente no país, entretanto que é permeado de discussões desde meados da década de 1930 e com diferentes experiências e trajetórias em diversas instituições de ensino superior. Nesse sentido, as autoras buscam conhecer e sistematizar os pontos de discussão entre a política pública recente e a trajetória e concepções institucionais. Elas apontam que essas concepções construídas, muitas vezes, se colocam em disputas com outras concepções buscam delimitar aquilo que compreendem como uma assistência estudantil ideal.

Um estudo que complementa este último é o de Imperatori (2017). Nele, a autora busca problematizar a assistência estudantil do ponto de vista de sua trajetória histórica até a implementação do PNAES. Ela traz elementos que nos auxiliam a compreender como determinados conceitos foram sendo construídos, partindo de uma pesquisa bibliográfica que se situa entre a assistência social e a educação. Além disso, a autora faz uma análise da compreensão da assistência estudantil enquanto um direito social e uma política pública.

\section{Resultados}

Abaixo, sintetizamos em uma tabela as informações dos trabalhos analisados, considerando o tipo de estudo, a data de publicação, o local (quando identificável) e o assunto. 
Tabela 1 - Síntese das publicações analisadas por autoria, data, tipo de estudo, local analisado e assunto

\begin{tabular}{|c|c|c|c|c|}
\hline Autor(es) & Data & Tipo de Estudo & Local & Assunto \\
\hline Mauricio & 2019 & Estudo de Caso & UFT & $\begin{array}{l}\text { "necessidade de ações em outras áreas do } \\
\text { PNAES" }\end{array}$ \\
\hline Fernandes & 2018 & Estudo de Caso & UFT & $\begin{array}{l}\text { "relação entre - assistência estudantil } \\
\text { qualidade de vida e desempenho acadêmico" }\end{array}$ \\
\hline Araújo & 2017 & Estudo de Caso & IFC & "relação entre PNAES e evasão" \\
\hline Vargas & 2017 & Estudo de Caso & Unipampa & $\begin{array}{l}\text { "implementação dos eixos do PNAES na } \\
\text { instituição" }\end{array}$ \\
\hline Abreu & 2017 & Estudo de Caso & IFPR & "relação entre PNAES e evasão" \\
\hline Farias & 2018 & Estudo de Caso & IFPB & $\begin{array}{l}\text { "percepção dos estudantes a respeito das } \\
\text { politicas de assistência" }\end{array}$ \\
\hline Magalhães & 2019 & Estudo de Caso & UFG & "avaliação da política de cotas" \\
\hline Botelho & 2016 & Estudo de Caso & UFV & $\begin{array}{l}\text { "movimento estudantil e políticas de } \\
\text { assistência" }\end{array}$ \\
\hline Senger & 2018 & Estudo de Caso & UTFPR & "relação entre PNAES e evasão" \\
\hline Creste & 2013 & Estudo de Caso & "Medicina" & "análise do serviço de apoio psicopedagógico" \\
\hline Marques & 2014 & Estudo de Caso & $\begin{array}{l}\text { UFCG e } \\
\text { UFPB }\end{array}$ & $\begin{array}{l}\text { "eixos do PNAES e ações focalizadoras, não } \\
\text { universais" }\end{array}$ \\
\hline Borsato & 2015 & Estudo de Caso & UFMS & $\begin{array}{l}\text { "ações com características assistenciais do } \\
\text { PNAES" }\end{array}$ \\
\hline Osse & 2008 & Estudo de Caso & UNB & $\begin{array}{l}\text { "relação entre assistência psicológica, } \\
\text { qualidade de vida residentes na moradia } \\
\text { estudantil" }\end{array}$ \\
\hline $\begin{array}{l}\text { Donida e } \\
\text { Santana }\end{array}$ & 2019 & Estudo de Caso & UF & $\begin{array}{l}\text { "análise das ações de apoio pedagógico da } \\
\text { instituição" }\end{array}$ \\
\hline Coulon & 2017 & Comparativo & $\begin{array}{l}\text { Brasil e } \\
\text { França }\end{array}$ & "transição e afiliação no ensino superior" \\
\hline $\begin{array}{l}\text { Matta, } \\
\text { Lebrão e } \\
\text { Heleno }\end{array}$ & 2017 & $\begin{array}{l}\text { Revisão } \\
\text { Bibliográfica }\end{array}$ & $\begin{array}{l}\text { Bases de } \\
\text { dados } \\
\text { científicas }\end{array}$ & $\begin{array}{l}\text { "vivência e adaptação acadêmica de estudantes } \\
\text { de ensino superior" }\end{array}$ \\
\hline Vargas & 2011 & Estudo de Caso & UFMG & $\begin{array}{l}\text { "relação entre assistência, permanência } \\
\text { estudantil e inserção profissional" }\end{array}$ \\
\hline $\begin{array}{l}\text { Andriola e } \\
\text { Suliano }\end{array}$ & 2015 & Estudo de Caso & UFC & $\begin{array}{l}\text { "impacto do REUNI e da interiorização da } \\
\text { UFC no Ceará" }\end{array}$ \\
\hline Silva & 2017 & Estudo de Caso & & $\begin{array}{l}\text { "concepções de docentes de exatas sobre } \\
\text { ações afirmativas" }\end{array}$ \\
\hline $\begin{array}{l}\text { Garrido e } \\
\text { Mercuri }\end{array}$ & 2013 & $\begin{array}{l}\text { Revisão } \\
\text { Bibliográfica }\end{array}$ & $\begin{array}{l}\text { Bases de } \\
\text { dados } \\
\text { científicas }\end{array}$ & "moradias estudantis universitárias" \\
\hline $\begin{array}{l}\text { Lacerda e } \\
\text { Valentini }\end{array}$ & 2018 & Estudo de Caso & & $\begin{array}{l}\text { "moradia estudantil e impacto no desempenho } \\
\text { acadêmico" }\end{array}$ \\
\hline Ristoff & 2014 & Analítico & Brasil & $\begin{array}{l}\text { "expansão do ensino superior e mudança no } \\
\text { perfil dos estudantes" }\end{array}$ \\
\hline $\begin{array}{l}\text { Andrade e } \\
\text { Teixeira }\end{array}$ & 2017 & Estudo de Caso & $\begin{array}{l}\text { "nova } \\
\text { universidade } \\
\text { multicampi" }\end{array}$ & $\begin{array}{l}\text { "PNAES e a intenção de permanência e } \\
\text { relação com desempenho acadêmico" }\end{array}$ \\
\hline $\begin{array}{l}\text { Recktenvald } \\
\text { et al }\end{array}$ & 2018 & Analítico & Brasil & $\begin{array}{l}\text { "PNAES e diferentes interpretações a partir da } \\
\text { experiência de gestores" }\end{array}$ \\
\hline $\begin{array}{l}\text { Dutra e } \\
\text { Santos }\end{array}$ & 2017 & Analítico & Brasil & $\begin{array}{l}\text { "PNAES e suas diferentes concepções } \\
\text { enquanto política pública" }\end{array}$ \\
\hline Imperatori & 2017 & Estudo de Caso & Brasil & "trajetória da assistência estudantil no país" \\
\hline
\end{tabular}

Fonte: Criado pelo autor. 


\section{Discussão dos resultados}

Os trabalhos analisados aqui se concentram em estudos de caso, em diferentes Instituições de Ensino Superior, buscando analisar a implementação do PNAES nessas instituições com a constituição de políticas institucionais de assistência estudantil. Abordam de forma geral a importância dos auxílios moradia, alimentação e transporte, destacando outras formas de auxílio ou a necessidade de se desenvolver outros tipos de suporte como o Apoio Pedagógico.

De maneira geral, a revisão bibliográfica apontou para uma lacuna, pois nenhum dos trabalhos abordou diretamente a ideia de Apoio Pedagógico. Em síntese, pode-se afirmar que, com exceção do trabalho de Donida e Santana (2019) não há publicações nestas bases de dados sobre ações de apoio pedagógico em serviços de apoio aos estudantes. Outra possibilidade de interpretação é o fato de haver poucas ações e programas voltados ao apoio pedagógico.

Assim, outras pesquisas sobre apoio pedagógico se fazem necessárias, como de Toti et al (2018) que traz um primeiro panorama mais específico sobre o apoio pedagógico a partir do levantamento de dados junto às universidades federais, sobre o quantitativo e perfil dos profissionais que lidam com apoio pedagógico, prevalecendo os pedagogos e psicólogos e os tipos de serviços oferecidos, sendo o mais citado o de atendimentos individuais.

Em trabalho semelhante, Toti e Dias (2020) também trazem algumas reflexões sobre o apoio pedagógico, em especial a sua ligação com as recentes políticas públicas de expansão do ensino superior, como o Reuni (BRASIL, 2007), o Pnaes (BRASIL, 2010) e a "Lei de Cotas" (BRASIL, 2012). De maneira geral, o conceito de apoio pedagógico, segundo eles, demonstra ter forte ligação com as políticas de expansão e com os conceitos de assistência e permanência estudantil.

Nos trabalhos analisados nesta revisão bibliográfica não é possível traçar uma ligação direta entre esses conceitos, no entanto, é possível considerar que as ações de apoio pedagógico estão ligadas a outras questões de permanência estudantil, como as políticas de assistência estudantil com suportes materiais, como moradia, alimentação, transporte, entre outros, além de se aproximarem de discussões sobre saúde mental, bem-estar e qualidade de vida ou de pertencimento, mais especificamente de afiliação, como propõe Coulon (2017).

Assim, podemos destacar a importância que o apoio pedagógico parece ter não somente como política institucional voltada à permanência dos estudantes, mas também como campo de pesquisa, dado os poucos materiais localizados até então. 


\begin{abstract}
Nota
1 Ristoff (2014) aponta as seguintes políticas analisadas: o Programa Universidade para Todos (Prouni), o Fundo de Financiamento ao Estudante do Ensino Superior (FIES), o Programa de Estímulo à Reestruturação e ao Fortalecimento das Instituições de Ensino Superior (PROIES), o Programa de Apoio a Planos de Reestruturação das Universidades Federais (REUNI), o Sistema de Seleção Unificada (Sisu), o Plano Nacional de Assistência Estudantil (PNAES), a Lei das Cotas nas Instituições Federais, a criação de novas universidades e novos campi das universidades federais, a política de interiorização e a criação dos Institutos Federais de Educação.
\end{abstract}

\title{
Referências
}

ABREU, Renata Pacheco. As expressões da evasão dos estudantes atendidos [pela] Política de Apoio Estudantil do Instituto Federal de Educação, Ciência e Tecnologia do Estado do Paraná - Campus Londrina. 2017. Dissertação (Mestre em Serviço Social e Política Social) - Universidade Estadual de Londrina - Programa de Pós-Graduação em Serviço Social e Política Social, Londrina, 2017.

ANDRADE, Ana Maria Jung de; TEIXEIRA, Marco Antônio Pereira. Áreas da política de assistência estudantil: relação com desempenho acadêmico, permanência e desenvolvimento psicossocial de universitários. Avaliação (Campinas) [online]. 2017, vol.22, n.2, pp.512-528. ISSN 1414-4077. http://dx.doi.org/10.1590/s1414-40772017000200014.

ANDRIOLA, Wagner Bandeira e SULIANO, Daniele Cirilo. Avaliação dos impactos sociais oriundos da interiorização da Universidade Federal do Ceará (UFC). Rev. Bras. Estud. Pedagog. [online]. 2015, vol.96, n.243, pp.282-298. ISSN 0034-7183. http://dx.doi.org/10.1590/S2176$6681 / 339512841$.

ARAUJO, Sandy Andreza De Lavor. Análise da efetividade da política de assistência estudantil do Instituto Federal do Ceará campus Iguatu, na garantia das condições de permanência no ensino superior. 2017. 210f. Dissertação (Mestrado em Políticas Públicas da Educação Superior) - Universidade Federal do Ceará, Programa de Pós-Graduação em Políticas Públicas da Educação Superior, Fortaleza, 2017.

BORSATO, Francieli Piva. A configuração da assistência estudantil da Universidade Federal de Mato Grosso do Sul após a implantação do PNAES. 2015. Dissertação (Mestre em Serviço Social e Política Social) - Universidade Estadual de Londrina - Programa de Pós-Graduação em Serviço Social e Política Social, Londrina, 2015.

BOTELHO, Cristiane Roque Pereira. Assistência estudantil na Universidade Federal de Viçosa: composições e tensões no/com o movimento estudantil. 2016. 99 f. Dissertação (Mestrado em Educação) Universidade Federal de Viçosa, Viçosa. 2016.

COULON, Alain. O ofício de estudante: a entrada na vida universitária. Educ. Pesqui. [online]. 2017, vol.43, n.4, pp.1239-1250. ISSN 1517-9702. http://dx.doi.org/10.1590/s15179702201710167954.

BRASIL. Decreto n 6.096, de 24 de abril de 2007. Institui o Programa de Apoio a Planos de Reestruturação e Expansão das Universidades Federais: REUNI. 2007. MEC. Disponível em: http://www.mec.gov.br. Acesso em: 04/08/2019. 
BRASIL. Decreto 7234. Institui o Plano Nacional de Assistência Estudantil e dá outras providências. Casa Civil. Brasília: julho de 2010. Disponível em http://www.planalto.gov.br/ccvil_3/ato2007-010/2010/decreto/d7234.htm. Acesso em 04/08/2019

BRASIL. Lei $N^{\circ} 12.711$, de 29 de agosto de 2012. Dispõe sobre o ingresso nas universidades federais e nas instituições federais de ensino técnico de nível médio e dá outras providências.

CRESTE, Cecília Emília de Oliveira. Psycho-pedagogical Support Service rendered to medicine students: a case study. 2013. 107 f. Dissertação (Mestrado em Ciências Humanas) - Universidade do Oeste Paulista, Presidente Prudente, 2013.

DIAS, Diana; SÁ, Maria José. The Impact of the Transition to HE: emotions, feelings and sensations. European Journal of Education, v(49), n(2), 2014, p.291-303.

DIAS, Diana. Democratização versus Massificação: um olhar do acesso ao sucesso. In: CNE (Conselho Nacional de Educação). Acesso ao Ensino Superior: Desafios para o Século XXI. Évora: Conselho Nacional de Educação, 2015, p.68-77.

DONIDA, Lais Oliva e SANTANA, Ana Paula. Apoio Pedagógico como proposta de educação para todos. Educ. Pesqui. [online]. 2019, vol.45, e192527. Epub 06-Jun-2019. ISSN 1517-9702. http://dx.doi.org/10.1590/s1678-4634201945192527.

DUTRA, Natália Gomes dos Reis e SANTOS, Maria de Fátima de Souza. Assistência estudantil sob múltiplos olhares: a disputa de concepções. Ensaio: aval.pol.públ.Educ. [online]. 2017, vol.25, n.94, pp.148-181. ISSN 0104-4036. http://dx.doi.org/10.1590/s0104-40362017000100006.

FARIAS, Leonardo Monte Silva Monteiro de. Assistência estudantil no Instituto Federal de Educação, Ciência e Tecnologia da Paraíba/ Campus João Pessoa: contradições, limites e desafios para a atenção aos estudantes do ensino superior. 2018. 104f. Dissertação (Mestrado Profissional em Educação) Universidade Federal da Paraíba, Programa de Pós-Graduação em Políticas Públicas, Gestão e Avaliação da Educação Superior, João Pessoa, 2018.

FERNANDES, Rebeca Vasconcelos. Programa de Bolsa Permanência - uma avaliação das possibilidades para a conclusão do ensino superior do estudante vulnerável na UFT/ campus de Gurupi. 2018. $152 \mathrm{f}$.

Dissertação (Mestrado Profissional em Gestão de Políticas Públicas) - Universidade Federal do Tocantins, Programa de Pós-Graduação em Gestão de Políticas Públicas, Palmas, 2018.

FERREIRA, Norma Sandra de Almeida. As pesquisas denominadas "estado da arte". Educação \& Sociedade, ano XXIII, no 79, Agosto/2002, p. 257-272. Acesso em: 04/09/2020. Disponível: https://www.scielo.br/pdf/es/v23n79/10857.pdf.

GARRIDO, Edleusa Nery e MERCURI, Elizabeth Nogueira Gomes da Silva. A moradia estudantil universitária como tema na produção científica nacional. Psicol. Esc. Educ. [online]. 2013, vol.17, n.1, pp.87-95. ISSN 2175-3539. http://dx.doi.org/10.1590/S141385572013000100009 .

HERINGER, Rosana. Um balanço de 10 anos de políticas de ação afirmativa no Brasil. Tomo (UFS), v. 1, p. 13-29, 2014. 
HERINGER, Rosana. Expansão do ensino superior no Brasil: acesso, diferenciação interna e políticas de inclusão (2011). In: XV Congresso Brasileiro de Sociologia, 2011, Curitiba (PR). Anais do XV Congresso da SBS.

IMPERATORI, Thaís Kristosch. A trajetória da assistência estudantil na educação superior brasileira. Serv. Soc. Soc. [online]. 2017, n.129, pp.285-303. ISSN 0101-6628.

http://dx.doi.org/10.1590/0101-6628.109.

LACERDA, Izabella Pirro e VALENTINI, Felipe. Impacto da Moradia Estudantil no Desempenho Acadêmico e na Permanência na Universidade. Psicol. Esc. Educ. [online]. 2018, vol.22, n.2, pp.413-423. ISSN 2175-3539. http://dx.doi.org/10.1590/2175-35392018022524.

MAGALHÃES, J. C. Gestão da politica de cotas em instituições federais de ensino superior: estudo na Universidade Federal de Goiás. 2019. 174 f. Dissertação (Mestrado em Administração Pública em Rede Nacional) - Universidade Federal de Goiás, Aparecida de Goiânia, 2019.

MARQUES, Sebastião Rodrigues. O Programa Nacional de Assistência Estudantil/PNAE: Uma análise a partir dos/ as assistentes sociais da Universidade Federal de Campina Grande (UFCG) e da Universidade Federal da Paraíba (UFPB). 2014. 268 f. Dissertação (Mestrado em Serviço Social) - Universidade Federal da Paraíba, João Pessoa, 2014.

MATTA, Cristiane Maria Barra da; LEBRAO, Susana Marraccini Giampietri e HELENO, Maria Geralda Viana. Adaptação, rendimento, evasão e vivências acadêmicas no ensino superior: revisão da literatura. Psicol. Esc. Educ. [online]. 2017, vol.21, n.3, pp.583-591. ISSN 2175-3539. http://dx.doi.org/10.1590/2175-353920170213111118.

MAURICIO, Nathanni Marrelli Matos. Avaliação do Programa Nacional de Assistência Estudantil na Universidade Federal do Tocantins. 2019. 177f. Dissertação (Mestrado Profissional em Gestão de Políticas Públicas) - Universidade Federal do Tocantins, Programa de Pós-Graduação em Gestão de Políticas Públicas, Palmas, 2019.

NEVES, Clarissa Eckert Baeta; SAMPAIO, Helena; HERINGER, Rosana. A institucionalização da pesquisa sobre ensino superior no Brasil. Revista Brasileira de Sociologia. v.6, n.12 Jan-Abr/2018.

OSSE, Cleuser Maria Campos. Pródromos e qualidade de vida de jovens na moradia estudantil da Universidade de Brasilia - UnB. 2008. 119 f. Dissertação (Mestrado em Psicologia Clínica)Universidade de Brasília, Brasília, 2008.

RECKTENVALD, Marcelo; MATTEI, Lauro e PEREIRA, Vilmar Alves. Avaliando o Programa Nacional de Assistência Estudantil (PNAES) sob a ótica das epistemologias. Avaliação (Campinas) [online]. 2018, vol.23, n.2, pp.405-423. ISSN 1414-4077. http://dx.doi.org/10.1590/s141440772018000200008 .

RISTOFF, Dilvo. O novo perfil do campus brasileiro: uma análise do perfil socioeconômico do estudante de graduação. Avaliação (Campinas) [online]. 2014, vol.19, n.3, pp.723-747. ISSN 14144077. http://dx.doi.org/10.1590/S1414-40772014000300010.

SAMPAIO, Helena. Diversidade e diferenciação no ensino superior no Brasil: conceitos para discussão. Rev. Bras. de Ciências Sociais, 2014, v(29)n(84), p.43-55. 
SENGER, Amália. Assistência estudantil no ensino superior: uma análise do Programa Auxilio Estudantil da Universidade Tecnológica Federal do Paraná, Campus Toledo. 2018. 189 f. Dissertação (Mestrado em Serviço Social) - Universidade Estadual do Oeste do Paraná, Toledo, 2018.

SILVA, Guilherme Henrique Gomes da. Educação matemática e ações afirmativas: possibilidades e desafios na docência universitária. Cad. Pesqui. [online]. 2017, vol.47, n.165, pp.820-846. ISSN 0100-1574. http://dx.doi.org/10.1590/198053143986.

TOTI, Michelle C. Silva; POLYDORO, Soely A. Jorge; ASSUMPÇÃO, Flavia V. S. Leite. O Apoio Pedagógico nas Universidades Federais Brasileiras. Congreso Internacional de Orientación para el aprendizaje em educación superior OAES. Santigo (Chile), 2018, 137-140.

TOTI, Michelle C. Silva; DIAS, Carlos Eduardo Sampaio Burgos. Conquistas, possibilidades e desafios para os serviços e seus profissionais. In: DIAS, Carlos Eduardo Sampaio Burgos; TOTI, Michelle C. Silva; SAMPAIO, Helena; POLYDORO, Soely Aparecida Jorge (orgs.). Os serviços de apoio pedagógico aos discentes no ensino superior brasileiro. São Carlos: Pedro \& João Editores, 2020, p.472-497.

TROW, Martin. Reflections on the Transition from Elite to Mass to Universal Access: Forms and Phases of Higher Education in Modern Societies since WWII. In: ALTBACH, Philip (ed.). International Handbook of Higher Education. Berkeley: Kluwer. 2005. Acesso: 19/01/2019.

Disponível em: https://escholarship.org/uc/item/96p3s213.

UNESCO (United Nations Educational, Scientific and Cultural Organization). Preface. In:

UNESCO (United Nations Educational, Scientific and Cultural Organization). Student Affairs and Services in Higher Education: Global Foundations, Issues and Best Practices. Paris, UNESCO, 2009.

VARGAS, Melissa Welter. Políticas públicas e desenvolvimento: limites e possibilidades na materialização da assistência estudantil no contexto da UNIPAMPA. 2017. 161f. Dissertação (Mestre em

Desenvolvimento Regional) - Universidade Regional do Noroeste do Estado do Rio Grande do Sul (Campus Ijui) - Programa de PósGraduação Stricto Sensu em Desenvolvimento Regional, Ijuí, 2017.

VARGAS, Michely de Lima Ferreira. Ensino superior, assistência estudantil e mercado de trabalho: um estudo com egressos da UFMG. Avaliação (Campinas) [online]. 2011, vol.16, n.1, pp.149-163. ISSN 1414-4077. http://dx.doi.org/10.1590/S1414-40772011000100008. 